\title{
Evaluation of QuEChERS Sample Preparation for Determination of Avermectins Residues in Ovine Muscle by HPLC-FD and UHPLC-MS/MS
}

\author{
Nelson M. G. Bandeira, Lucila C. Ribeiro, Tiele M. Rizzetti, Manoel L. Martins, \\ Martha B. Adaime, Renato Zanella and Osmar D. Prestes*
}

Laboratório de Análises de Resíduos de Pesticidas (LARP), Departamento de Química, Universidade Federal de Santa Maria, 97105-900 Santa Maria-RS, Brazil

\begin{abstract}
A fast and sensitive method using high performance liquid chromatography-fluorescence detection (HPLC-FD) and ultra-high performance liquid chromatography tandem mass spectrometry (UHPLC-MS/MS) was developed and validated for the determination of avermectins residues in ovine muscle samples. QuEChERS (quick, easy, cheap, effective, rugged and safe) sample preparation based on acetonitrile extraction followed by partitioning with $\mathrm{NaCl}$ and $\mathrm{Na}_{2} \mathrm{SO}_{4}$ and dispersive solid-phase extraction (d-SPE) clean-up with $\mathrm{C} 18$ was applied. $\mathrm{Na}_{2} \mathrm{SO}_{4}$ was used instead of $\mathrm{MgSO}_{4}$ due to lower amounts of co-extractives in the final extract. The procedure was validated according to the Commission Decision 2002/657/EC. The method showed determination coefficients $\left(\mathrm{r}^{2}\right)$ higher than 0.99 , recoveries between 93.2 and $124.3 \%$ for spike levels between 0.5 and 2.0 times the maximum residues limit (MRL) values. The repeatability and intermediate precision RSD values ranged from 1 to $19 \%$. Decision limits $(\mathrm{CC} \alpha)$ and detection capabilities (CC $\beta$ ) ranged from 10.7 to $59.4 \mu \mathrm{g} \mathrm{kg}^{-1}$ and 11.4 to $68.8 \mu \mathrm{g} \mathrm{kg}^{-1}$, respectively. Method performance was successfully evaluated by analyzing real samples and proficiency test with a z-score in the range of \pm 1 .
\end{abstract}

Keywords: veterinary drugs residue, liquid chromatography, animal tissue

\section{Introduction}

The macrocyclic lactones (ML) are an important veterinary drug class, which are extremely effective against endo and ectoparasites. ${ }^{1}$ These compounds are structurally divided in avermectins (ivermectin, abamectin, doramectin, eprinomectin, emamectin and selamectin) and milbemycins (milbemycin oxime, moxidectin and nemadectin). ${ }^{2}$ Avermectins are the most widely applied anti-parasitic drugs in livestock, used for treatment of diseases and prevention. ${ }^{3}$ Nowadays, Brazil is a worldwide important meat producer and exporter. ${ }^{4}$ In accordance with SINDAN, ${ }^{5}$ avermectins represent more than $40 \%$ of all commercialized anti-parasitic drugs.

To ensure that produced meat are in accordance with food safety and quality criteria required by national and international regulations, an important tool to monitor and assure this compliance is the National Residue and Contaminants Control Plan (PNCRC). ${ }^{6}$ However, in the last years Brazilian beef products received international

*e-mail: osmar.prestes@ufsm.br border restrictions due to presence of ivermectin residues above maximum residue limit (MRL) established in $10 \mu \mathrm{g} \mathrm{kg}^{-1} .7$ In the PNCRC, special attention is devoted to control residues and contaminants in cattle, swine and chicken. The exportation of these commodities in 2013 represented more than U\$ 15.9 billion dollars. The ovine production is an important meat source in the Brazilians northeast and southern regions. This commodity provides meat, milk and wool. Currently, Brazil has around 17.6 million ovine animals, furthermore, ovine meat produced in Brazil are not included in the matrices analyzed in the PNCRC and no information about the presence of residues and contaminants is available for ovine meat. ${ }^{8}$ In the literature, He et al. ${ }^{9}$ describe a method for analysis of macrocyclic lactones in ovine, swine, bovine and chicken muscle by liquid chromatography tandem mass spectrometry (LC-MS/MS). An automated procedure using accelerated solvent extraction for determination of ivermectin in meat-based processed food by highperformance liquid chromatography with ultraviolet-visible detector (HPLC-UV) is also reported. ${ }^{10}$ Procedures based in solvent extraction and solid-phase extraction (SPE) 
clean-up for determination of macrocyclic lactones in animal tissues by HPLC-fluorescence detection (FD) ${ }^{11-14}$ by LC-MS/MS ${ }^{15}$ and both ${ }^{16}$ are reported. The use of SPE cartridges for cleaning purposes has some disadvantages. Perhaps the most important of them, when compared with dispersive-SPE (d-SPE), is the time consuming execution. A simple, fast and easy procedure is desirable considering sample preparation time and analysts practice. Since Anastassiades et al. ${ }^{17}$ proposed QuEChERS (quick, easy, cheap, effective, rugged and safe), different versions have been published. Initially developed for pesticide residues extraction from fruits ${ }^{18}$ and vegetables, ${ }^{19}$ this method have been applied for veterinary drugs residues analysis in different food of animal origin as milk, ${ }^{20}$ beef, ${ }^{21,22}$ poultry, ${ }^{23}$ honey, ${ }^{24,25}$ sea food, ${ }^{26}$ liver and eggs. ${ }^{27-29}$

The most applied technique for determination of avermectins is the high performance liquid chromatography. Fluorescence detection demands derivatization steps, although it is been extensively applied considering its sensitivity, price, and simplicity. On the other hand, mass spectrometry technique requires no derivatization steps. Furthermore, tandem MS systems provide high selectivity and detectability and can be used for identification purposes. The use of ultra-high performance liquid chromatography (UHPLC) allows to use smaller columns of lower particle size with low mobile phase flow, these imply in higher resolution, lower running times and less mobile phase residues. ${ }^{30}$

Since QuEChERS method has been recently reported with great advantages while it is simple and practical, the aim of this study was to develop and validate a modified QuEChERS method, for the determination of residues of abamectin, doramectin, eprinomectin and ivermectin in ovine muscle by HPLC-FD and UHPLC-MS/MS.

\section{Experimental}

\section{Reagents and materials}

Acetonitrile $(\mathrm{MeCN})$, methanol $(\mathrm{MeOH})$, acetic acid and tetrahydrofuran (THF), all LC grade were obtained from JT Baker (Phillipsburg, USA). N-Methylimidazole (NMIM) and trifluoracetic anhydride (TFAA) were provided by Acros Organics (Fair Lawn, USA). Anhydrous magnesium sulfate $\left(\mathrm{MgSO}_{4}\right)$ and anhydrous sodium acetate $(\mathrm{NaAc})$ were acquired from JT Baker (Phillipsburg, USA) and anhydrous sodium sulfate $\left(\mathrm{Na}_{2} \mathrm{SO}_{4}\right)$ was purchased from Merck (Darmstadt, Germany). Ammonium formate, sodium chloride $(\mathrm{NaCl})$, sodium citrate dehydrate $\left(\mathrm{Na}_{3} \mathrm{Cit} .2 \mathrm{H}_{2} \mathrm{O}\right)$ and disodium citrate sesquihydrate $\left(\mathrm{Na}_{2} \mathrm{HCit} .1 .5 \mathrm{H}_{2} \mathrm{O}\right)$ were purchased from Sigma-Aldrich (Saint Louis, USA). Bondesil
C18 sorbent $(40 \mu \mathrm{m})$ for d-SPE clean-up was obtained from Agilent Technologies (Santa Clara, USA). Ultra-pure water $(18 \mathrm{M} \Omega)$ was obtained with a Milli-Q system from Millipore (Molsheim, France). Nylon filters $13 \mathrm{~mm}(0.2 \mu \mathrm{m})$ were purchased from Vertical Chromatography (Bangkok, Thailand), glass vials with capacity of $2 \mathrm{~mL}$ (Agilent, Santa Clara, USA), polypropylene tubes with screw caps of 50 and $15 \mathrm{~mL}$ (Sarstedt, Germany) and microtube of $2 \mathrm{~mL}$ (Axygen Scientific, Union City, USA) were used.

Certified standards with high purity (from 90 to 97\%) of abamectin, doramectin, emamectin, eprinomectin and ivermectin were purchased from Dr. Ehrenstorfer (Darmstadt, Germany). Emamectin was selected as surrogate standard since it is an avermectin licensed only for treatment in aquiculture and its presence in ovine tissues is not expected. Individual stock solutions at $1000 \mathrm{mg} \mathrm{L}^{-1}$ were prepared in $\mathrm{MeCN}$ and standard mixture with all analytes at $10 \mathrm{mg} \mathrm{L}^{-1}$ was prepared in $\mathrm{MeCN}$ and stored at $-18^{\circ} \mathrm{C}$.

Instruments

Vortex shaker (model QL-901) from BioMixer (Paulínia, Brazil), analytical balances (UX-420H) from Shimadzu (Kyoto, Japan) and APX-200 from Denver Instruments Ltda. (Santo André, Brazil), refrigerated centrifuges NT 825 from Novatecnica (Piracicaba, Brazil) and SL 703 from Solab (Piracicaba, Brazil) and a stirrer hot plate from Logen Scientific (Diadema, Brazil), used for derivatization step, were used.

The HPLC-FD system consisted of a PerkinElmer Separations Series 200 (Shelton, USA) containing: HPLC pump mixer system, fluorescence detector, vacuum degasser and autosampler, all 225 series. All these components were controlled by PerkinElmer Network Chromatography Interface Series 900 (Shelton, USA).

UHPLC-MS/MS analysis were performed using Acquity Waters system (Milford, USA) equipped with a Xevo TQ MS/MS triple quadrupole detector, an autosampler, a binary pump and a column temperature controller. Waters MassLynx 4.1 software (Milford, USA) was used for instrument control and data processing.

\section{Samples}

All ovine muscle samples were obtained from supermarket stores from Santa Maria, Brazil. The samples were processed with a Varimix food processor (Mondragon, Mondragón, Spain) and were stored frozen at approximately $-18^{\circ} \mathrm{C}$ until being used for the experiments. Blank samples were analyzed before use to confirm that they were free of targeted avermectins. 


\section{Sample preparation}

In order to evaluate the sample preparation step, four different QuEChERS methods based on acetonitrile extraction and d-SPE clean-up were tested. Ovine muscle was spiked at $50 \mu \mathrm{g} \mathrm{kg}^{-1}$ with the target compounds and six replicates were carried out with the proposed extraction methods. Recoveries ranging between $70-120 \%$ and relative standard deviation $(\mathrm{RSD}) \leq 20 \%$ were considered acceptable. ${ }^{31}$ The spiking procedure was performed by adding the standard mixture solution containing the avermectins compounds to homogenized blank ovine muscle samples. The contact time of the compounds with the sample before the extraction procedure was kept at a minimum of $1 \mathrm{~h}$.

\section{Original QuEChERS method (unbuffered QuEChERS method $)^{17}$}

$10 \mathrm{~g}$ of muscle were weighed into a $50 \mathrm{~mL}$ tube and extracted with $10 \mathrm{~mL}$ of $\mathrm{MeCN}$ shaking vigorously by hand for $1 \mathrm{~min}$, followed by partitioning promoted by the addition of $1 \mathrm{~g} \mathrm{NaCl}$ and $4 \mathrm{~g} \mathrm{MgSO}_{4}$. This mixture was shaken $(1 \mathrm{~min})$ and centrifuged at $2137 \times \mathrm{g}$ for $8 \mathrm{~min}$ at $10{ }^{\circ} \mathrm{C}$. For the d-SPE clean-up step, $4 \mathrm{~mL}$ of upper layer phase were transferred to a $15 \mathrm{~mL}$ centrifuge tube containing $100 \mathrm{mg} \mathrm{C18}$ and $600 \mathrm{mg} \mathrm{MgSO}_{4}$. The tube was shaken $(1 \mathrm{~min})$ and then centrifuged for $8 \mathrm{~min}$ at $2137 \times \mathrm{g}$ at $10^{\circ} \mathrm{C}$. Finally, the cleaned extract was filtered with $0.2 \mu \mathrm{m}$ nylon syringe filters.

\section{Acetate buffered QuEChERs method ${ }^{32}$}

$15 \mathrm{~g}$ of muscle were weighed into a $50 \mathrm{~mL}$ tube and extracted with $15 \mathrm{~mL}$ of MeCN containing $1 \%(\mathrm{v} / \mathrm{v})$ acetic acid. After that, $6 \mathrm{~g}$ of $\mathrm{MgSO}_{4}$ and $1.5 \mathrm{~g}$ of $\mathrm{NaAc}$ were added and the tube was shaken by hand for $1 \mathrm{~min}$. Subsequently, the mixture was centrifuged at $2137 \times \mathrm{g}$ for $8 \mathrm{~min}$ at $10^{\circ} \mathrm{C}$ and the clean-up step was performed as described for the original QuEChERS method.

\section{Citrate buffered QuEChERs method ${ }^{33}$}

$10 \mathrm{~g}$ of muscle were weighed into a $50 \mathrm{~mL}$ tube and extracted with $10 \mathrm{~mL}$ of $\mathrm{MeCN}$. A mixture of salts consisting of $4 \mathrm{~g} \mathrm{MgSO}_{4}, 1 \mathrm{~g} \mathrm{NaCl}, 1 \mathrm{~g} \mathrm{Na}_{3}$ Cit. $2 \mathrm{H}_{2} \mathrm{O}$ and $0.5 \mathrm{~g} \mathrm{Na}_{2} \mathrm{HCit} .1 .5 \mathrm{H}_{2} \mathrm{O}$ was added and the tube was shaken vigorously by hand for $1 \mathrm{~min}$. Subsequently, the mixture was centrifuged at $2137 \times \mathrm{g}$ for $8 \mathrm{~min}$ at $10^{\circ} \mathrm{C}$. The cleanup step was performed as described before.

\section{Proposed and validated extraction method}

$5 \mathrm{~g}$ of muscle were weighed into a $50 \mathrm{~mL}$ tube and extracted with $5 \mathrm{~mL}$ of $\mathrm{MeCN}$ shaking vigorously by hand for $1 \mathrm{~min}$, followed by partitioning promoted by the addition of $2 \mathrm{~g} \mathrm{NaCl}$ and $4 \mathrm{~g} \mathrm{Na}_{2} \mathrm{SO}_{4}$. The tube was shaken vigorously by hand $(1 \mathrm{~min})$ and centrifuged at $2137 \times \mathrm{g}$ for $8 \mathrm{~min}$ at $10^{\circ} \mathrm{C}$. For the d-SPE clean-up step, $4 \mathrm{~mL}$ of upper layer phase was cleaned with $500 \mathrm{mg} \mathrm{C} 18$, the tube was shaken by hand (1 min). Finally, the tube was centrifuged at $2137 \times \mathrm{g}$ for $8 \mathrm{~min}$ and the upper layer was filtered.

\section{Derivatization step and HPLC-FD analysis}

Prior HPLC-FD determination, the cleaned and filtered extracts obtained by the described methods were derivatized based on Rübensam et al. ${ }^{34}$ For this, $1 \mathrm{~mL}$ of each extract was evaporated under gentle nitrogen stream and reconstituted with $395 \mu \mathrm{L}$ of $\mathrm{MeCN}$. To this solution, $40 \mu \mathrm{L}$ of NMIM was added and mixed by vortex (10 s). After that $40 \mu \mathrm{L}$ of TFAA and $25 \mu \mathrm{L}$ of acetic acid were rapidly added and homogenized. The vial was closed and covered for light protection. Afterwards, the vial was incubated in water bath at $60 \pm 5^{\circ} \mathrm{C}$ for $20 \mathrm{~min}$. The solution was kept at room temperature before injection.

\section{HPLC-FD analysis}

The HPLC-FD chromatographic separation was performed with a reverse phase column Acclaim ${ }^{\mathrm{TM}} 120 \mathrm{C} 8$ $(250 \times 4.6 \mathrm{~mm} \times 5 \mu \mathrm{m})$ and a guard column (C18) from Thermo Scientific (Sunnyvale, USA). The elution mode was achieved by isocratic conditions with a mobile phase containing MeCN, THF and $\mathrm{MeOH}$ (96:3:1 v/v/v) using a flow rate at $0.8 \mathrm{~mL} \mathrm{~min}^{-1}$. The injection volume was $10 \mu \mathrm{L}$. The fluorescence of derivatives compounds was detected at the excitation and emission wavelengths of 365 and $470 \mathrm{~nm}$, respectively. All calculations were performed using the TotalChrom 3.0 software from PerkinElmer (Shelton, USA).

\section{UHPLC-MS/MS analysis}

The UHPLC separation was performed with an Acquity BEH C 18 column $(50 \times 2.1 \mathrm{~mm} ; 1.7 \mu \mathrm{m}$ particle size $)$ from Waters (Milford, USA) maintained at $45{ }^{\circ} \mathrm{C}$. Gradient elution, with flow rate of $0.225 \mu \mathrm{L} \mathrm{min}{ }^{-1}$ was performed with (A) $10 \mathrm{mmol} \mathrm{L}^{-1}$ ammonium formiate and (B) $\mathrm{MeCN}$ with $0.1 \%$ formic acid. The gradient program was started with $50 \%$ (B) and the proportion was increased linearly to $80 \%$ (B) in $1 \mathrm{~min}$, then to $100 \%$ (B) in $3 \mathrm{~min}$, at which it was held for $0.5 \mathrm{~min}$ before it was returned to the initial condition. The temperature of the sample manager was kept at $4{ }^{\circ} \mathrm{C}$ and $10 \mu \mathrm{L}$ of sample was injected.

Mass spectrometric analyses were performed using selected reaction monitoring (SRM) mode. All MS parameters were optimized under electrospray ionization 
Table 1. UHPLC-MS/MS conditions for avermectins analysis

\begin{tabular}{lcccccc}
\hline Compound & $\mathrm{t}_{\mathrm{R}} / \mathrm{min}$ & $\begin{array}{c}1^{\text {st }} \text { transition } \\
\text { quantification }\end{array}$ & $\mathrm{CE} / \mathrm{V}$ & $\begin{array}{c}2^{\text {nd }} \text { transition } \\
\text { identification }\end{array}$ & $\mathrm{CE} / \mathrm{V}$ & Ion ratio \\
\hline Eprinomectin & 2.2 & $915.6>186.0$ & 41 & $915.6>144.0$ & 35 & 0.67 \\
Abamectin & 2.5 & $890.6>305.2$ & 25 & $890.6>567.4$ & 11 & 0.91 \\
Doramectin & 2.7 & $916.6>331.2$ & 23 & $916.6>593.4$ & 14 & 0.81 \\
Ivermectin & 3.2 & $892.6>307.2$ & 24 & $892.6>569.4$ & 14 & 0.42 \\
\hline
\end{tabular}

$t_{R}=$ retention time $; C E=$ collision energy.

(ESI) in positive mode following these conditions: desolvation and cone gas $\left(\mathrm{N}_{2}\right)$ flow rate were set at 600 and $80 \mathrm{~L} \mathrm{~h}^{-1}$, respectively. A capillary voltage of $2.5 \mathrm{kV}$, desolvation temperature at $350{ }^{\circ} \mathrm{C}$ and source temperature at $150{ }^{\circ} \mathrm{C}$ were used. The collision gas was argon at a flow rate of $0.15 \mathrm{~mL} \mathrm{~min}^{-1}$. The retention time, transitions used for quantification and identification, collision energy and ion ratio were listed in Table 1.

\section{Method validation}

The proposed method was validated for avermectins determinations by HPLC-FD and UHPLC-MS/MS based on European Commission Decision 2002/657/EC criteria. ${ }^{35}$ The following parameters were evaluated in this study for both chromatography techniques: specificity, linearity, accuracy, precision (repeatability and intermediate precision), decision limit ( $\mathrm{CC} \alpha)$, detection capability (CC $\beta$ ), limit of detection (LOD) and limit of quantification (LOQ). For evaluation of accuracy (as recovery $\%$ ) and precision of the developed method, blank ovine muscle samples were spiked $(n=6)$ at 10,20 and $30 \mu \mathrm{g} \mathrm{kg}{ }^{-1}$ with abamectin; 20, 40 and $60 \mu \mathrm{g} \mathrm{kg}^{-1}$ with doramectin; 25,50 and $75 \mu \mathrm{g} \mathrm{kg}^{-1}$ with eprinomectin and 5,10 and $20 \mu \mathrm{g} \mathrm{kg}^{-1}$ with ivermectin.

\section{Results and Discussion}

\section{HPLC-FD and UHPLC-MS/MS analysis}

For the derivatization step, sample extracts were dried by nitrogen flow and reconstituted with acetonitrile and derivatizing reagents (NMIM and TFAA). In accordance with Rübensam et al..$^{16}$ and Cerkvenik-Flajsa et al. ${ }^{36}$ to obtain a trifluoroacetylester derivative, the use of acetic acid $(25 \mu \mathrm{L})$ and the incubation at $65{ }^{\circ} \mathrm{C}$ for $20 \mathrm{~min}$ were necessary to generate a stable eprinomectin fluorescent derivative. In agreement with Cerkvenik-Flajsa et al., ${ }^{36}$ without these conditions eprinomectin showed a low response and could not be analyzed by HPLC-FD. The chromatographic conditions were optimized in order to improve the derivative avermectins separation. An isocratic elution with $\mathrm{MeCN}$, THF and $\mathrm{MeOH}$ (96:3:1) proved to be efficient and less than 15 min were required to separate the compounds in the following elution sequence: eprinomectin $\left(t_{R}=7.5 \mathrm{~min}\right)$, abamectin $\left(t_{R}=10.2 \mathrm{~min}\right)$, doramectin $\left(t_{R}=11.5 \mathrm{~min}\right)$, and ivermectin $\left(t_{R}=13.8 \mathrm{~min}\right)$. Emamectin $\left(t_{R}=9.2 \mathrm{~min}\right)$ was also used as internal standard like Rübensam et al. ${ }^{34}$ Other works ${ }^{16,36,37}$ use similar mobile phase composition containing high amount of $\mathrm{MeCN}, \mathrm{MeOH}$ or mixtures of both solvents. A typical HPLC-FD chromatogram is shown in Figure 1. Separation of the analytes was achieved and no interferences were found when a blank extract was evaluated. As obtained by Hernández-Borges et al., ${ }^{37}$ the better conditions for excitation and emission wavelength were 365 and $470 \mathrm{~nm}$, respectively.

To obtain proper response using UHPLC-MS/MS, the optimization of MS parameters was performed by direct infusion in the MS of a standard solution $\left(100 \mu \mathrm{g} \mathrm{L}^{-1}\right)$ of each compound. We selected ESI interface because of the higher sensitivity obtained. Although, other strategies to increase detectability, like the possibility of stable adduct formation $[\mathrm{M}+\mathrm{Na}]^{+}$or $\left[\mathrm{M}+\mathrm{NH}_{4}\right]^{+}$, was verified. The MS/MS spectra of $\left[\mathrm{M}+\mathrm{NH}_{4}\right]^{+}$presented two abundant fragments with higher relative intensities when compared with $\mathrm{Na}^{+}$adducts. Thus, in this work we added $10 \mathrm{mmol} \mathrm{L}^{-1}$ ammonium formiate to the mobile phase to ensure the formation of ammonium adducts $\left[\mathrm{M}+\mathrm{NH}_{4}\right]^{+}$as a precursor ion by $\mathrm{ESI}(+) .{ }^{38} \mathrm{In}$ order to develop a fast and efficient analysis, an UHPLC column $(50 \mathrm{~mm} \times 1.7 \mu \mathrm{m})$ was used resulting in narrow peaks and increased efficiency. The mobile phase employed permitted the separation of avermectins in less than $4 \mathrm{~min}$. A good peak shape and reproducible chromatographic signals were obtained using a dwell time of $0.02 \mathrm{~s}$. Figure 2 shows the SRM chromatogram for each avermectin (quantification transition was shown) of a matrix matched solution at $50 \mu \mathrm{g} \mathrm{kg}^{-1}$.

\section{Sample preparation}

In this work, four sample preparation strategies based on QuEChERS method (original, acetate, citrate and 


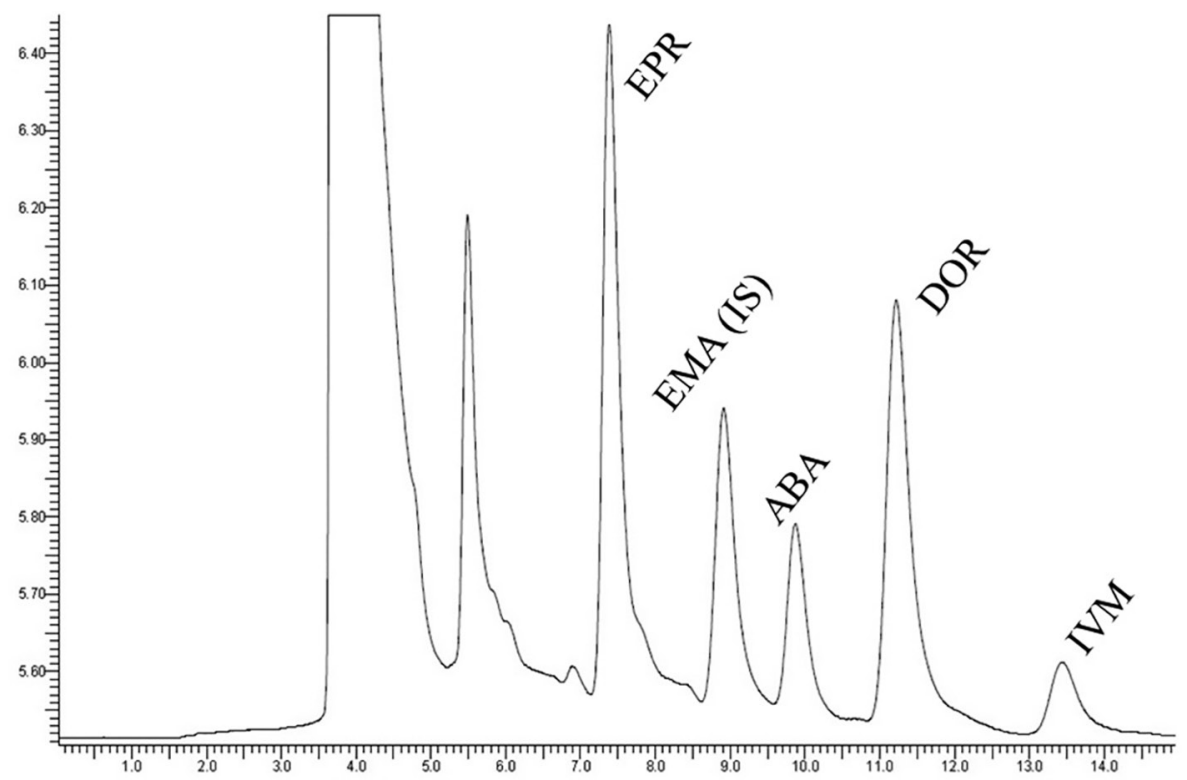

Figure 1. HPLC-FD chromatogram obtained from an ovine blank muscle sample spiked with EPR (eprinomectin), ABA (abamectin), DOR (doramectin) and IVE (ivermectin) at $50 \mu \mathrm{g} \mathrm{kg}^{-1}$ with the proposed extraction method. EMA (emamectin) was used as internal standard (IS).

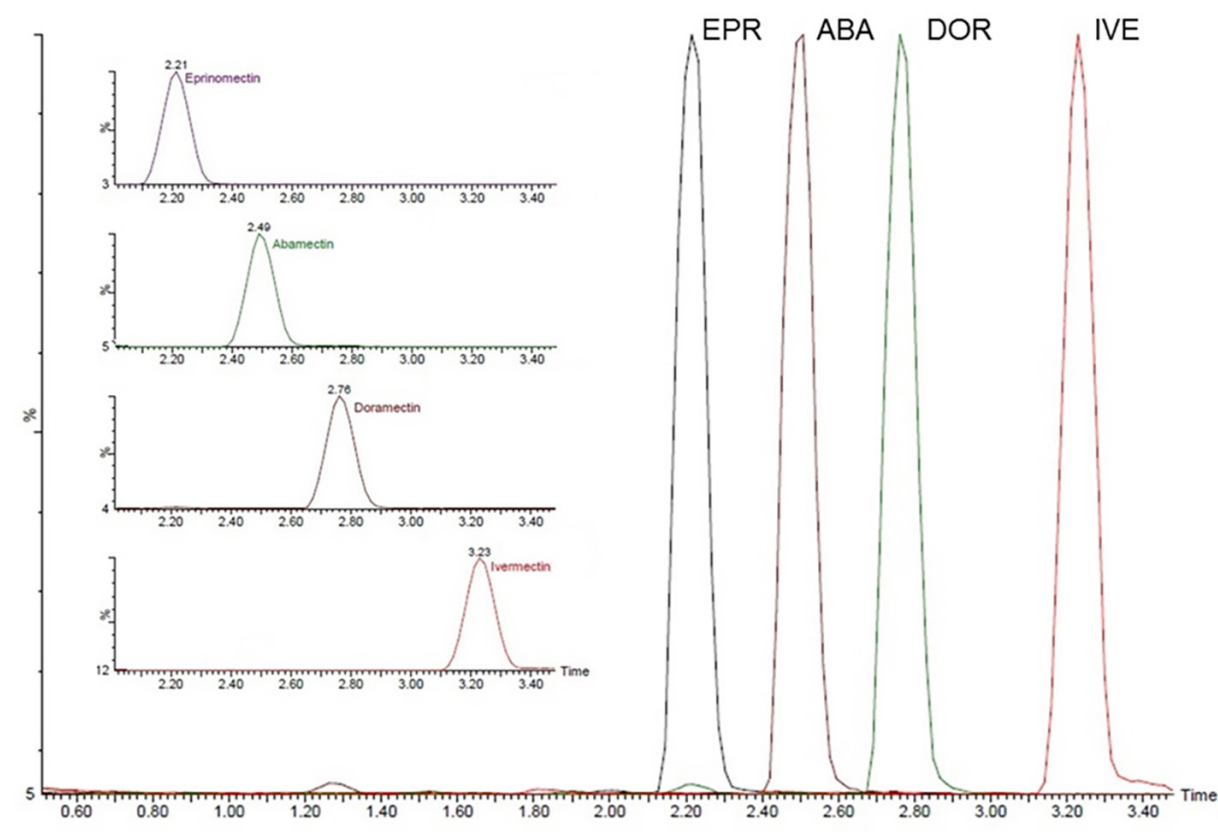

Figure 2. UHPLC-MS/MS chromatogram obtained at SRM mode from a blank ovine muscle sample spiked with EPR (eprinomectin), ABA (abamectin) DOR (doramectin) and IVE (ivermectin) at $50 \mu \mathrm{g} \mathrm{kg}^{-1}$ with the proposed extraction method.

proposed versions) were evaluated based on recoveries and precision results. Thus, original QuEChERS method was used considering that it was successfully used for the determination of anthelmintic drug residues in milk. ${ }^{39}$ The acetate and citrate buffered QuEChERS methods were used for the extraction of a wide range of veterinary drugs from different food of animal origin. ${ }^{40}$ Figure 3 shows the obtained results for comparison of the four QuEChERS methods.

All analyzed compounds were extracted with the four evaluated methods, but with different recovery efficiencies.
Original QuEChERS method provided recoveries within 91.6 to $115.5 \%$ with RSD between 6.8 and $16.3 \%$. Acetate buffered method presented recoveries in the range of 86.7 to $98.2 \%$, with RSD $>20.5 \%$ for all compounds. The citrate QuEChERS showed recoveries between 78.3 and $92.5 \%$, with RSD $<20.3 \%$. In comparison with all evaluated procedures, original $\mathrm{QuEChERS}$ method provides a cleaner extract due to the $\mathrm{pH}$ value higher than buffered QuEChERS versions, ${ }^{41}$ resulting in extracts with lower concentration of co-extractives. 


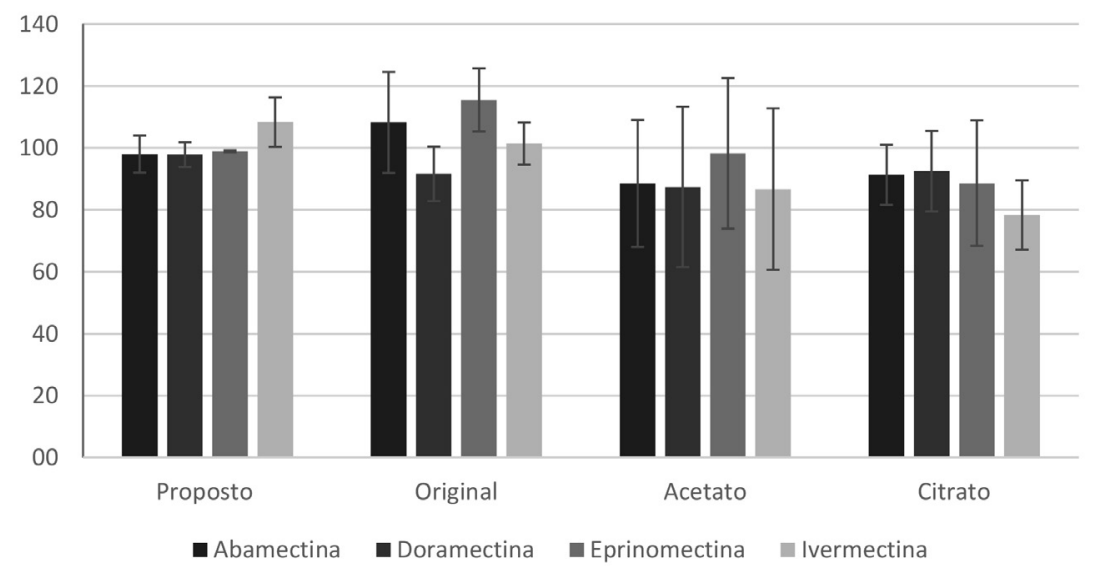

Figure 3. Recovery comparison of the proposed method versus QuEChERS original, acetate and citrate from spiked muscle samples $(\mathrm{n}=6)$ at $50 \mu \mathrm{g} \mathrm{kg}{ }^{-1}$, obtained by HPLC-FD.

The proposed method presented recoveries between 97.8 and $108.3 \%$ and RSD $\leq 8.0 \%$ for all analytes. From these preliminary results, we decided to validate the proposed method, aiming the low extraction of the coextractives compounds from ovine muscle. Considering that sodium sulfate is a worse dry agent than magnesium sulfate, water is not completely removed from acetonitrile..$^{42}$ As discussed by Kaufmann et al., ${ }^{43}$ the presence of water residues increases the acetonitrile polarity. In this way, extraction yields of low polarity compounds, as fat and proteins, decrease. Still, the combination of higher $\mathrm{pH}$ of unbuffered QuEChERS with a higher polarity extraction solvent promoted cleaner extracts and better results. Thus, the use of sodium sulfate was preferable instead of magnesium sulfate. It is important to develop a sample preparation procedure that extracts as few co-extractive components as possible. These compounds from the muscle sample may alter the chromatographic behavior of the analytes and cause matrix effects, leading to inaccurate quantification.

In recent years many sample preparation approaches have been used for determination of macrocyclic lactones in foodstuff, as presented in Table 2. Matrix solidphase dispersion (MSPD) was applied for ivermectin determination in milk with a LOQ of $48.3 \mu \mathrm{g} \mathrm{kg}^{-1}$ good accuracy for a spiking level of 96.5 and $482.5 \mu \mathrm{g} \mathrm{kg}{ }^{-1} \cdot{ }^{44}$ Original QuEChERS was used for determination of abamectin, doramectin, ivermectin and eprinomectin in meat with reliable results from 2.5 to $150 \mu \mathrm{g} \mathrm{kg}^{-1}$ and LOQ of $2.5 \mu \mathrm{g} \mathrm{kg}^{-1}{ }^{45}$ Liquid-liquid extraction with low temperature partitioning (LLE-LTP) and SPE clean-up were used to determine abamectin and ivermectin residue in edible oils with LOQs from 0.7 to $1.1 \mu \mathrm{g} \mathrm{kg}^{-1}$ and recoveries between 71.1 and $119.3 \%$ with RSD from 3.2 to $11.1 \%{ }^{46}$ Heated liquid-liquid extraction was used for determination of abamectin, doramectin and ivermectin residues in butter with recoveries ranging from 72.4 to $106.5 \%$ and RSD from 2.7 to $15.7 \%$ for concentrations of 2,4 and $6 \mu \mathrm{g} \mathrm{kg}^{-1}$. 47 Beyond QuEChERS, the other techniques imply in higher number of steps and sample manipulation, which increases analysis time and sources of errors.

\section{Method validation}

The validation procedure, necessary to ensure quality and results comparability, followed European Commission Decision 2002/657/EC..$^{35}$ The European Union MRLs, for abamectin, doramectin and eprinomectin in ovine muscle are 20,40 and $50 \mu \mathrm{g} \mathrm{kg}^{-1}$, respectively. Ivermectin has MRLs established just for fat, liver and kidney (100, 100 and $30 \mu \mathrm{g} \mathrm{kg}^{-1}$, respectively). Therefore, the reference limit adopted for ivermectin in this work was $10 \mu \mathrm{g} \mathrm{kg}^{-1}$. The method selectivity was obtained by the analysis of blank samples and was checked for any interference around the retention time of the target analytes. No interfering compounds were observed by both HPLC-FD and UHPLC-MS/MS methods. The linearity, obtained based on spiking levels for each analyzed compound, resulted in satisfactory calibration curves in the range of 0.5 to $2 \times$ MRL with determination coefficients $\left(r^{2}\right)$ higher than 0.99 for all compounds and RSD below $10.6 \%$.

LOD and LOQ values presented in Table 3 were achieved based on the signal to noise ratio, and were similar to previous published studies. ${ }^{16}$ The acquired LOD were between 4.0-5.8 and 0.8-4.2 $\mu \mathrm{g} \mathrm{kg}^{-1}$ for HPLC-FD and UHPLC-MS/MS, respectively. The LOQm were between 5.9-27.4 and 2.5-12.5 $\mu \mathrm{g} \mathrm{kg}^{-1}$ for HPLC-FD and UHPLC-MS/MS, respectively. As described by Kaufmann et al., ${ }^{48}$ the evaluation of $\mathrm{CC} \alpha$ and $\mathrm{CC} \beta$ is necessary to estimate the level of confidence of the analytical results, preventing the reporting of false positive and false negative. In this work, $\mathrm{CC} \alpha$ and $\mathrm{CC} \beta$ were established regarding the respective 
Table 2. Comparison of four different techniques applied for determination of avermectins in food of animal origin with the proposed method

\begin{tabular}{|c|c|c|c|c|c|c|c|c|c|c|c|}
\hline Technique & Sample & $\begin{array}{l}\text { Sample } \\
\text { amount }\end{array}$ & Solvent & $\begin{array}{l}\text { Additional } \\
\text { technique }\end{array}$ & $\begin{array}{c}\text { Extract } \\
\text { volume / } \mathrm{mL}\end{array}$ & Specifications & Evaporation & $\begin{array}{l}\text { Dilution } \\
\text { factor }\end{array}$ & Steps & $\begin{array}{c}\text { LOQ / } \\
\left(\mu \mathrm{gg}^{-1}\right)\end{array}$ & Reference \\
\hline MSPD & milk & $0.5 \mathrm{~mL}$ & - & SPE & - & $\begin{array}{c}\text { washing: } 5 \times 1 \mathrm{~mL} \text { of } \\
\text { hexane; elution: } 5 \times 5 \mathrm{~mL} \\
\text { of } \mathrm{MeOH}: \text { ethyl acetate } \\
(1: 1, \mathrm{v} / \mathrm{v})\end{array}$ & yes & - & 14 & 48.3 & 44 \\
\hline QuEChERS & meat & $3.0 \mathrm{~g}$ & $\begin{array}{c}10 \mathrm{~mL} \mathrm{MeCN} \\
\text { containing } 0.5 \% \\
\text { ammonia }\end{array}$ & d-SPE & all & $\begin{array}{c}150 \mathrm{mg} \mathrm{C} 18 \text { and } 900 \mathrm{mg} \text { of } \\
\mathrm{MgSO}_{4}\end{array}$ & yes & - & 11 & 2.5 & 45 \\
\hline \multirow[t]{2}{*}{ LLE } & edible oils & $2.5 \mathrm{~g}$ & $\begin{array}{c}2.5 \mathrm{~mL} \text { hexane + } \\
5 \mathrm{~mL} \mathrm{MeCN}\end{array}$ & LTP & 1 & $16 \mathrm{~h}$ at $-30{ }^{\circ} \mathrm{C}$ & yes & 2 & 7 & 0.3 to 1.1 & 46 \\
\hline & & & & SPE & 3 & $\begin{array}{c}\text { alumina-B cartridge; } \\
\text { conditioning: } 5 \mathrm{~mL} \\
\text { MeCN; washing: } 5 \mathrm{~mL} \\
\text { hexane }(\mathrm{MeCN}) \\
\text { elution: } 2 \times 5 \mathrm{~mL} \mathrm{MeOH}\end{array}$ & & & 11 & & \\
\hline $\begin{array}{l}\text { Heated } \\
\text { ultrasound } \\
\text { assisted LLE }\end{array}$ & butter & $\begin{array}{c}0.5 \mathrm{~g} \\
\left(50^{\circ} \mathrm{C}\right)\end{array}$ & $\begin{array}{c}10 \mathrm{~mL} \\
\text { MeCN:ethyl } \\
\text { acetate:water } \\
(90: 4: 6, \mathrm{v} / \mathrm{v} / \mathrm{v}) \text { at } \\
50^{\circ} \mathrm{C}\end{array}$ & - & - & - & yes & 2 & 8 & $\begin{array}{c}0.09 \text { to } \\
0.16\end{array}$ & 47 \\
\hline QuEChERS & muscle & $5 \mathrm{~g}$ & $5 \mathrm{~mL} \mathrm{MeCN}$ & d-SPE & 4 & $500 \mathrm{mg} \mathrm{C} 18$ & no & - & 6 & 0.8 to 5.8 & proposed \\
\hline
\end{tabular}

MSPD: matrix solid-phase dispersion; LLE: liquid-liquid extraction; SPE: solid-phase extraction; d-SPE: dispersive solid-phase extraction; LTP: low temperature partitioning; LOQ: limit of quantification.

MRL of each compound. All results were presented in the Table 3. Values for $\mathrm{CC} \alpha$ and $\mathrm{CC} \beta$ are often alike due to the reference for calculation, which is based on the MRL adopted. Similar results for $\mathrm{CC} \alpha$ and $\mathrm{CC} \beta$ were achieved for bovine muscle by Rübensam et al. ${ }^{16}$ These results are shown in Table 3.

The applied sample preparation method resulted in good analyte recoveries, ranging from 100.3 to $124.3 \%$ (RSD < 10.6\%) and 92.6 to $114.6 \%$ (RSD < 19\%) when analysis were performed at 3 spike levels with HPLC-FD and UHPLC-MS/MS, respectively. Method precision was satisfactory for all analytes, and is in compliance with the Commission Decision 2002/EC/657 ${ }^{35}$ requirements. The recovery levels obtained with this method reached similar levels presented by Hou et al..$^{15}$ and Kinsella et al. ${ }^{28}$ The recovery (RSD) values from the intermediate precision assay ranged between $76.3-93.9 \%(4-7 \%)$ and $91.2-112.3$ (7-14\%) for HPLC-FD and UHPLC-MS/MS, respectively, as summarized in Table 3 . The present method was verified in a proficiency test organized by the Rede Metrologica RS (Brazil). A total of 19 laboratories participated in this study. The study consisted of lyophilised muscle sample containing ivermectin as incurred residue. The sample was identified correctly, and no false positive or false negative results were observed. z-Score values obtained by our laboratory were in the range of \pm 1 , highlighting the suitability of the proposed method. Otherwise, this method was applied to the simultaneous determination of abamectin, doramectin, eprinomectin and ivermectin residues in 11 real samples of ovine muscle obtained from local supermarkets. None of them presented residues at concentrations levels above the LOD established by the method.

Table 3. Method limits of detection (LOD) and quantification (LOQ), limit of decision (CC $\alpha$ ), detection capability (CC $\beta$ ), accuracy and precision results of validated method for HPLC-FD and UHPLC-MS/MS

\begin{tabular}{|c|c|c|c|c|c|c|c|c|c|c|c|c|c|c|c|c|}
\hline \multirow{4}{*}{ Compound } & \multicolumn{8}{|c|}{ HPLC-FD } & \multicolumn{8}{|c|}{ UHPLC-MS/MS } \\
\hline & \multicolumn{4}{|c|}{ Method limits / $\left(\mu \mathrm{g} \mathrm{kg}^{-1}\right)$} & \multicolumn{4}{|c|}{ Recovery (RSD) / \% } & \multicolumn{4}{|c|}{ Method limits / $\left(\mu \mathrm{g} \mathrm{kg}^{-1}\right)$} & \multicolumn{4}{|c|}{ Recovery (RSD) / \% } \\
\hline & \multirow{2}{*}{ LOD } & \multirow{2}{*}{ LOQ } & \multirow{2}{*}{$\mathrm{CC} \alpha$} & \multirow{2}{*}{$\mathrm{CC} \beta$} & \multicolumn{3}{|c|}{ Spike level / $\left(\mu \mathrm{g} \mathrm{kg}^{-1}\right)$} & \multirow{2}{*}{$\begin{array}{c}\text { Intermediate } \\
\text { precision }\end{array}$} & \multirow{2}{*}{ LOD } & \multirow{2}{*}{ LOQ } & \multirow{2}{*}{$\mathrm{CC} \alpha$} & \multirow{2}{*}{$\mathrm{CC} \beta$} & \multicolumn{3}{|c|}{ Spike level / $\left(\mu \mathrm{g} \mathrm{kg}^{-1}\right)$} & \multirow{2}{*}{$\begin{array}{c}\text { Intermediate } \\
\text { precision }\end{array}$} \\
\hline & & & & & Low & Medium & High & & & & & & Low & Medium & High & \\
\hline Abamectin & 5.8 & 8.7 & 21.3 & 22.6 & $121.5(3)$ & $100.4(4)$ & $104.9(3)$ & $78.3(4)$ & 1.5 & 5 & 23.5 & 26.9 & $104.7(17)$ & $92.6(11)$ & $96.8(13)$ & $98.3(6)$ \\
\hline Doramectin & 8.5 & 12.6 & 42.6 & 45.2 & $100.3(7)$ & $104.0(4)$ & $102.6(6)$ & $87.3(7)$ & 3.3 & 10 & 47.3 & 54.7 & $100.2(16)$ & $100.0(11)$ & $93.2(15)$ & $91.4(14)$ \\
\hline Eprinomectin & 18.4 & 27.4 & 59.4 & 68.8 & $109.0(10)$ & $118.7(10)$ & $124.3(4)$ & $93.9(7)$ & 4.2 & 12.5 & 53.2 & 56.5 & $99.2(13)$ & $98.8(4)$ & $98.6(8)$ & $112.3(7)$ \\
\hline Ivermectin & 4.0 & 5.9 & 10.7 & 11.4 & $105.1(9)$ & $106.9(4)$ & $107.2(11)$ & $76.3(5)$ & 0.8 & 2.5 & 13.1 & 16.2 & $114.6(19)$ & $110.3(17)$ & $100.0(1)$ & $91.2(5)$ \\
\hline
\end{tabular}




\section{Conclusions}

Rapid, reliable and sensitive HPLC-FD and UHPLCMS/MS methods for simultaneous determination of the abamectin, doramectin, eprinomectin and ivermectin residues in ovine muscle were successfully developed and validated. However, UHPLC-MS/MS is recommendable, once the technique increase selectivity, and can avoid falsepositive results. The method was successfully applied to routine analysis of avermectins residues in food of animal origin. Because of the easy clean-up step, the proposed method is fast, has a lower cost and is easy to perform. Furthermore, the small volume of acetonitrile required in this method is beneficial to analysts and the environment.

\section{Acknowledgments}

Authors gratefully acknowledge the financial support and fellowship grants from the Conselho Nacional de Desenvolvimento Científico e Tecnológico (CNPq) and the Coodernação de Aperfeiçoamento de Pessoal de Nível Superior (CAPES), Brazil.

\section{References}

1. Kotze, A. C.; Ruffell, A. P.; Knox, M. R.; Kelly, G. A.; Vet. Parasitol. 2014, 203, 294.

2. Prichard, R.; Ménez, C.; Lespine, A.; Int. J. Parasitol.: Drugs Drug Resist. 2012, 02, 134.

3. Capanema, L. X. L.; Velasco, L. O. M.; Souza, J. O. B.; Noguti, M. B.; BNDES Setorial 2007, 25, 157.

4. http://www.brazilianbeef.org.br/texto.asp?id=8, accessed in August 2016.

5. http://www.agricultura.gov.br/animal/qualidade-dos-alimentos/ residuos-e-contaminantes, accessed in August 2016.

6. Mauricio, A. Q.; Lins, E. S.; Alvarenga, M. B.; Anal. Chim. Acta 2009, 637, 333.

7. http://ec.europa.eu/food/safety/rasff, accessed in August 2016.

8. http://www.ibge.gov.br/home/estatistica/indicadores/ agropecuaria/producaoagropecuaria, accessed in August 2016.

9. He, L.; Zhao, D.; Su, Y.; Liu, Y.; Nie, J.; Lian, J.; J. AOAC Int. 2009, 92, 348

10. Abend, A. M.; Chung, L.; McCollum, D. G.; Wuelfing, W. P.; J. Pharm. Biomed. Anal. 2003, 31, 1177.

11. Roudant, B.; Analyst 1998, 123, 2541.

12. Ali, M. S.; Sun, T.; McLeroy, G. E.; Phillippo, E. T.; J. AOAC Int. 2000, 83(1), 31 .

13. Nagata, T.; Miyamoto, F.; Hasegawa, Y.; Ashizawa, E.; J. AOAC Int. 2003, 86, 490.

14. Chou, H. K.; Lai, C. Y.; Chen, T. H.; Yen, G. C.; J. Food Drug Anal. 2004, 12, 146.
15. Hou, X.; Jiang, H.; Ding, S.; Zhang, S.; Li, X.; Shen, J.; J. AOAC Int. 2006, 89, 1110.

16. Rübensam, G.; Barreto, F.; Hoff, R. B.; Pizzolato, T. M.; Food Control 2013, 29, 55.

17. Anastassiades, M.; Lehotay, S. J.; Stajnbaher, D.; Schenck, F. J.; J. AOAC Int. 2003, 86, 412.

18. Kurz, M. H. S.; Gonçalves, F. F.; Adaime, M. B.; da Costa, I. F. D.; Primel, E. G.; Zanella, R.; J. Braz. Chem. Soc. 2008, 19, 1129.

19. Kemmerich, M.; Rizzetti, T. M.; Martins, M. L.; Prestes, O. D.; Adaime, M. B.; Zanella, R.; Food Anal. Methods 2015, 8, 728.

20. Brondi, S. H. G.; Souza, G. B.; Nogueira, A. R. A.; Camargo, L. A.; Majaron, R. F.; Quim. Nova 2013, 36, 153.

21. Kang, J.; Fan, C. L.; Chang, Q. Y.; Bu, M. N.; Zhao, Z. Y.; Wang, W.; Pang, G. F.; Anal. Methods 2014, 6, 6285.

22. Nakajima, T.; Nagano, C.; Sasamoto, T.; Hayashi, H.; Kanda, M.; Kanai, S.; Takeba, K.; Matsushima, Y.; Takano, I.; J. Food Hyg. Soc. Jpn. 2012, 53, 243.

23. Rocha, D. G.; Santos, F. A.; Silva, J. C.; Augusti, R.; Faria, A. F.; J. Chromatogr. A 2015, 1379, 83.

24. Wang, J.; Leung, D.; Drug Test Anal. 2012, 1, 103.

25. Orso, D.; Floriano, L.; Ribeiro, L. C.; Bandeira, N. M. G.; Prestes, O. D.; Zanella, R.; Food Anal. Methods 2015, 9, 1638.

26. Villar-Pulido, M.; Gilbert-López, B.; García-Reyes, J. F.; Martos, N. R.; Molina-Díaz, A.; Talanta 2011, 85, 1419.

27. Stubbings, G.; Bigwood, T.; Anal. Chim. Acta 2009, 637, 68.

28. Kinsella, B.; Whelan, M.; Cantwell, H.; McCormack, M.; Furey, A.; Lehotay, S. J.; Danaher, M.; Talanta 2010, 83, 14.

29. Frenich, A. G.; Aguilera-Luiz, M. M.; Vidal, J. L. M.; RomeroGonzález, R.; Anal. Chim. Acta 2010, 661, 150.

30. Danaher, M.; Howells, L. C.; Crooks, S. R. H.; Cerkvenik-Flajs, V.; O'Keeffe, M.; J. Chromatogr. B 2006, 844, 175.

31. European Commission, Directorate-General for Health and Food Safety; Document No. SANTE/11945/2015; Guidance Document on Analytical Quality Control and Method Validation Procedures for Pesticides Residues Analysis in Food and Feed, European Commission, 2015.

32. Lehotay, S. J.; J. AOAC Int. 2007, 90, 485.

33. CEN Method, EN 15662; Foods of Plant Origin - Determination of Pesticide Residues Using GC-MS and/or LC-MS/MS Following Acetonitrile Extraction/Partitioning and Cleanup by Dispersive SPE - QuEChERS-Method, European Committee for Standardization, 2008.

34. Rübensam, G.; Barreto, F.; Hoff, R. B.; Kist, T. L.; Pizzolato, T. M.; Anal. Chim. Acta 2011, 705, 24.

35. European Commission, Commission Decision 2002/657/EC Implementing Council Directive 96/23/EC Concerning the Performance of Analytical Methods and the Interpretation of Results; Off. J. Eur. Communities: Legis., 17.8.2002, L221, 8. 
36. Cerkvenik-Flajsa, V.; Milcinski, L.; Süssinger, A.; Hodoscek, L.; Danaher, M.; Antonic J.; Anal. Chim. Acta 2010, 663, 165.

37. Hernández-Borges, J.; Ravelo-Pérez, L. M.; Hernández-Suárez, E. M.; Carnero, A.; Rodríguez-Delgado, M. A.; J. Chromatogr. A 2007, 1165, 52.

38. Tao, Y.; Yu, G.; Chen, D.; Pan, Y.; Liu, Z.; Wei, H.; Peng, D.; Huang, L.; Wang, Y.; Yuan, Z.; J. Chromatogr. B 2012, 897, 64.

39. Whelan, M.; Kinsella, B.; Furey, A.; Moloney, M.; Cantwell, H.; Lehotay, S. J.; Danaher, M.; J. Chromatogr. A 2010, 1217, 4612.

40. Park, K. H.; Choi, J. H.; El-Aty, A. M. A.; Cho, S. K.; Park, J. H.; Kwon, K. S.; Park, H. R.; Kim, H. S.; Shin, H. C.; Kim, M. R.; Shim, J. H.; Meat Sci. 2012, 92, 749.

41. Sousa, F. A.; Costa, A. I. G.; Queiroz, M. E. L. R.; Pinho, R. F. T. G. P.; Neves, A. A.; Cromatographia 2013, 76, 67.

42. Schenck, F. J.; Callery, P.; Gannett, P. M.; Daft, J. R.; Lehotay, S. J.; J. AOAC Int. 2002, 85, 1170.
43. Kaufmann, A.; Butcher, P.; Maden, K.; Walker, S.; Widmer, M.; Anal. Chim. Acta 2014, 820, 56.

44. García-Major, M. M.; Gallego-Picó, A.; Garcinuño, R. M.; Fernández-Hernando, P.; Durand-Alegría, J. S.; Food Chem. 2012, 134, 553.

45. Rúbies, A.; Antkowiak, S.; Granados, M.; Companyó, R.; Centrich, F.; Food Chem. 2015, 181, 57.

46. Huang, J. X.; Lu, D. H.; Wan, K.; Wang, F. H.; Chin. Chem. Lett. 2014, 25, 635.

47. Macedo, F.; Marsico, E. T.; Conte-Júnior, C. A.; Resende, M. F.; Brasil, T. F.; Netto, A. D. P.; Food Chem. 2015, 179, 239.

48. Kaufmann, A.; Anal. Chim. Acta 2009, 637, 144.

Submitted: June 20, 2016

Published online: August 19, 2016

FAPERGS/CAPES has sponsored the publication of this article. 